\title{
Executive Functions as Predictors of School Performance and Social Relationships: Primary and Secondary School Students $\ddagger$
}

\author{
Juan Pablo Zorza1, Julián Marino² and Alberto Acosta Mesas ${ }^{1}$ \\ 1 Universidad de Granada (Spain) \\ ${ }^{2}$ Universidad Nacional de Córdoba (Argentina)
}

\begin{abstract}
This study examined the relationship between executive functions (EFs) and school performance in primary and secondary school students aged 8 to 13 years ( $N=146, M=10.4,45.8 \%$ girls). EFs were evaluated using the Trail Making Test (TMT), Verbal Fluency (VF), and the Stroop Test. Students' GPAs and teachers' assessment of academic skills were used to measure school performance. To evaluate the students' social behavior, participants were asked to rate all their classmates' prosocial behavior and nominate three students with whom they preferred to do school activities; teachers also provided evaluations of students' social skills. EF measures explained $41 \%\left(p=.003, f^{2}=.694\right)$ of variability in school performance and $29 \%\left(p=.005, f^{2}=.401\right)$ of variance in social behavior in primary school students. The predictive power of EFs was found to be lower for secondary school students, although the TMT showed significant prediction and explained $13 \%\left(p=.004, f^{2}=.149\right)$ of variance in school performance and $15 \%\left(p=.008, f^{2}=.176\right)$ in peer ratings of prosocial behavior. This paper discusses the relevance of EFs in the school environment and their different predictive power in primary and secondary school students.
\end{abstract}

Received 26 June 2015; Revised 17 March 2016; Accepted 28 March 2016

Keywords: executive functions, prosociality, school performance, social preference.

Executive Functions (EFs) represent a heterogeneous set of metacognitive processes that direct behavior towards a goal, organize sub-goals, consider future behaviors, and are globally related to planning and problem-solving (Diamond, 2013; Pessoa, 2009). They depend on working memory, inhibitory control, and cognitive flexibility, which are considered to be their basic processes (Miyake et al., 2000). Overall, EFs control cognitive functions and regulate basic abilities such as attention, memory, semantic processing, and affective processes so that behavior flexibly adapts to different situations and demands.

EFs encompass metacognitive operations that are highly useful at school (Blair \& Diamond, 2008). They may be used to develop abstract thinking (e.g., to solve logic problems) or to facilitate social behavior (e.g., respecting turn-taking in conversations) (Best, Miller, \& Naglieri, 2011; Riggs, Jahromi, Razza, Dillworth-Bart, \& Mueller, 2006). Further, it has been observed that some executive operations are specifically related to certain academic domains: working memory has been linked to mathematics performance and cognitive flexibility

Correspondence concerning this article should be addressed to Juan Pablo Zorza. Departamento Psicología Experimental. Universidad de Granada. Campus Universitário de Cartuja s/n. 18071. Granada (Spain). Phone: +34-958243772. Fax: +34-958246239.

Email: zorzajpz@gmail.com

$\ddagger$ The original version of this article was published with an incorrect author name. A notice detailing this has been published and the error rectified in the online PDF and HTML copies. to the language domain (van der Ven, Kroesbergen, Boom, \& Leseman, 2012). Nonetheless, these relations may vary depending on the students' age. Best et al. (2011) reported that correlations between EFs and performance in mathematics and language were stronger at ages 5-6 and 8-9 than in the years in between, i.e. 6-8, and remained stable during adolescence. Generally speaking, it has been proposed that building EFs has a positive impact on students' achievement. What is more, students repeating a school year, or belonging to socially and culturally disadvantaged groups may benefit from EF training (Thorell, Lindqvist, Bergman Nutley, Bohlin, \& Klingberg, 2009).

Associations have also been found between EFs and social behavior, and a large number of studies have linked problems in executive functioning to social adjustment problems. A limited working memory capacity, low levels of inhibitory control, and diminished semantic executive control negatively affect social interactions, thus fostering reactive aggressiveness (Ellis, Weiss, \& Lochman, 2009) and impulsivity (Romer et al., 2009). In children and adolescents, a deficit in EF development is associated with behavioral problems and disruptive behaviors (Jacobson, Williford, \& Pianta, 2011; Riggs, Blair, \& Greenberg, 2004). This association is not explained by intelligence (Mahone et al., 2002) or some sociodemographic variables like ethnic group (Hughes \& Ensor, 2008; Morgan \& Lilienfeld, 2000). In the study by Jacobson et al. (2011) 
the EFs measures significantly predicted emotional reactivity, self-control, criminal behavior and social relation difficulties in children who were advancing to secondary school, regardless of intelligence or some sociodemographic aspects.

Furthermore, although the relation between EFs and helpfulness towards classmates and peer acceptance (Hay, Payne, \& Chadwick, 2004) has been less studied, it is known that EFs do play an important role in self-control of behavior and emotional self-regulation (Blair \& Diamond, 2008; Checa, Rodríguez-Bailón, \& Rueda, 2008; Eisenberg, Valiente, \& Eggum, 2010; Riggs et al., 2006; Rueda, Checa, \& Rothbart, 2010). In early adolescence, students with a higher level of effortful control show greater empathy (Zorza, Marino, de Lemus, \& Acosta, 2013) and are more likely to be accepted and chosen by peers (Checa et al., 2008). Overall, EFs are closely linked to the cognitive and affective processes involved in social cognition (Adolphs, 2009; Razza \& Blair, 2009).

The purpose of this study was to determine the predictive power of EFs for school performance, social preference among peers and prosocial behaviors, and to ascertain whether it remains the same between primary and secondary school. The predictive power of EFs on school performance may be more important during the early years of primary education than in later years (Altemeier, Abbott, \& Berninger, 2008). Transition from one school level to another requires significant cognitive and social adjustment, and students have to adapt not only to the new school's size and space, but also to new procedural rules, changes regarding peer and class grouping, and greater personal responsibility (Jacobson et al., 2011; Steinberg, 2005). Further, unlike primary education, peer acceptance and preference criteria in secondary school are not influenced by adults' opinions (parents, teachers) to the same extent. In secondary school, students are more independent and may apply more heterogeneous criteria than in primary school (Rodkin, Farmer, Pearl, \& van Acker, 2000). Considering the institutional and psychological changes involved in the transition from primary to secondary school, our study seeks to observe whether the EFs relate to the school variables in the same or in a different way according to school level. Therefore, two separate studies will be carried out for each level.

The tasks applied to evaluate EFs in this studyTMT, Verbal Fluency, and the Stroop Test-assess working memory, inhibitory control and cognitive flexibility, and are considered to be 'first generation tests' (Gruber \& Goschke, 2004). Notably, all these tests require engagement in several executive and cognitive operations simultaneously, although only one predominates in each task. One of the advantages attributed to these classic tests is that they have greater ecological validity (Chan, Shum, Toulopoulou, \& Chen, 2008), given that various cognitive skills are often simultaneously used and coordinated when performing school activities.

The predictive power of EFs was expected to be greater for school performance than for social behavior variables and further, to remain the same for school performance between primary and secondary school students. It was also expected to be positive for students' social preferences and peer-assessed prosocial behavior, and likewise, for teachers' perceptions of social skills, particularly at primary school. If these assumptions were confirmed, a battery of simple and easy-to-deliver tasks would be obtained to provide significant predictions of academic performance and social achievement that could be used as general indices of achievement and school adjustment.

\section{Method}

\section{Participants}

The participants for the study were children from two state schools in the city of Granada (Spain): a primary school (58.9\% of total sample) and a secondary school $(41.1 \%)$. Mean age of participants was 10.9 years $(S D=1.4) ; 45.8 \%$ of participants were girls. Primary school students were currently in third $(N=19)$, fourth $(N=21)$, fifth $(N=21)$ or sixth grade $(N=25)$. The remaining students were in their first year of secondary school $(N=60)$ and were in two different classes ( $N=30$ in each class). Students who had repeated a school year were not included. The correlation between age and grade was very high $(r=0.96, p<.001)$; hence, age and grade level analyses were considered to be interchangeable. The majority of the $3^{\text {rd }}$ grade primary school students were 8 years old, and the $1^{\text {st }}$ grade secondary school students were 12 .

The socioeconomic status of the participants, measured according to level of their parent's education and income, was similar, i.e. middle-low. The majority of children were Caucasian born in Spain. Latin American immigrants accounted for only $5.4 \%$ of participants. Consent was obtained from school principals and parents and the study received ethics approval by the committee responsible.

\section{Executive Function Measures}

\section{Trail Making Test (TMT)}

The classic Reitan and Wolfson paper-and-pencil version was delivered (Lezak, 1995). The TMT consists of two parts (A and B); in each, participants are required to connect 25 circles placed randomly on an A4 size sheet of paper, in sequential order, as quickly 
as possible, without lifting the pencil from the paper. Circles in part A are numbered from 1 to 25 ; in part B, circles are numbered from 1 to 13 , and lettered from A to L. Part B requires participants to alternate between numbers and letters in sequential order, i.e., $1-A-2-B$, etc. Errors were pointed out immediately by the test deliverer, and the score for each part of the test was taken from the time (in seconds) it took them to complete the task. Performance time was measured with a stop watch. The two parts of the test provide information about numerous processes: perceptive processes, motor processes, cognitive flexibility, working memory, sustained attention and processing speed (Sánchez-Cubillo et al., 2009). Specifically, part B is more related to cognitive flexibility (Kortte, Horner, \& Windham, 2002).

\section{Verbal Fluency $(V F)$}

Three tests were delivered in which participants were required to say as many words as possible in one minute (Piatt, Fields, Paolo, \& Tröster, 1999). In the first test, the request was semantic (naming animals); in the second, grammatical (naming verbs); and in the third, phonological (words starting with the letter P). The total number of valid words produced in each test was noted down. In the semantic test, neither supraordinate categories such as 'fish' or 'birds', nor subordinate categories such as 'dog breeds' were taken into account. Responses were digitally recorded and tests were delivered in counterbalanced order. The VF tests have been related to numerous EFs: information monitoring, working memory, sustained attention, inhibitory control, cognitive flexibility, and to executive control of semantic processing (Koren, Kofman, \& Berger, 2005; Marino, Acosta Mesas, \& Zorza, 2011). This relationship depends on demand. When it is semantic, the EFs implication is lower than when it is verbal or phonological.

\section{Stroop Test}

A two-part version of this test was delivered (Lezak, 1995). In the first part of the test (C), participants were given an A4 sheet of paper with 112 color-printed (blue, green, red, and black) words denoting colors (blue, green, red, and black). All words were printed in a different color from the color designated by the word. Participants were required to read the written word as quickly as possible. In the second part of the test $(\mathrm{CP})$, participants were again given an A4 sheet of paper with the same number of words, designating colors as before, and also printed in different colors from the color designated by the word; participants were required to say the color in which the words were printed. Performance time was measured with a stop watch. Performance in each part of the test was scored by dividing the number of correct answers by the number of seconds taken to complete the test. Answers are usually correct in part $C$ while in part $\mathrm{CP}$ errors are more frequent. The latter requires more inhibitory control resources as the involuntary tendency to read the word and answer by naming the color in which it is written should be inhibited. The performance of this task has been related to inhibitory control processes (Garon, Bryson, \& Smith, 2008; Jurado \& Rosselli, 2007).

\section{School Performance Measures}

\section{Grade Point Average}

The Grade Point Average (GPA) achieved at the end of the school year by each student was obtained, including all relevant subjects taken. Despite the lack of correspondence between the subjects taught at primary school level and those taught at secondary school, this mean performance index nonetheless allows comparative analysis.

\section{Teacher-perceived academic capacities}

All class tutors ${ }^{1}$ completed the Intelligence-Socialization Teacher Rating Scale (Carrión, Hernández, \& Gregorio, 1999) to evaluate each of their students. The scale comprised 24 items, scored from 1 to 10 (maximum), to assess students' Intelligence, Socialization, and Respect for Authority. Intelligence (I-TRS) was included as a factor in order to obtain additional information about the participants' academic capacities, given that it provides information on each student's academic skills and their potential to successfully perform school tasks (e.g., "the ability to put learned knowledge into practice"), as perceived by the class tutor. Reliability of this scale is very high $(\alpha=.94)$.

\section{Measurement of social behavior among peers}

\section{Social preference}

Each student received a list with the names of all their classmates. Students were asked to choose three classmates with whom they preferred to share school activities and spend their free time. Students were also required to choose three classmates with whom they would prefer not to share these activities. Participants were assured complete confidentiality of their replies. The social preference score for each student was based

${ }^{1}$ In the Spanish educational system, each class has a tutor who is a teacher from the school. The tutor is responsible for each student's follow-up regarding academic performance and social behavior. Also, the tutor informs each student's family about their progress or difficulties. 
on three calculations (Maassen, van Boxtel, \& Goossens, 2005). First, the sums of positive and negative nominations were calculated. Second, adjusted numbers of positive and negative nominations were obtained by dividing each of the two aforementioned sums by the total number of students in the class, minus one. Third, the adjusted number of negative nominations was subtracted from the adjusted number of positive nominations.

\section{Peer-assessed and teacher-perceived prosocial behavior}

Participants had to rate on a scale from 1 to 5 (maximum) how much each classmate helped fellow students when the latter experienced learning difficulties or interpersonal conflicts at school (López Sánchez, 2006). The total sum of scores given to each student by peers was obtained and subsequently divided by the number of students in the class, minus one. Additionally, as previously described, class tutors completed a separate Intelligence-Socialization Teacher Rating Scale (Carrión et al., 1999) to evaluate each of their students. The Socialization (S-ITR) factor, which evaluates each student's social integration and cooperative attitude toward classmates (e.g., "the ability to cooperate positively with peers in settling disputes peacefully"), was included as an index of prosocial behavior. Reliability of this factor is also very high $(\alpha=.93)$.

\section{Procedure}

Three months before the end of the school year, the questionnaires to obtain information on social preference and prosocial conduct were delivered collectively in class and the EF-related tasks were delivered individually in a quiet, calm environment in each school. The Intelligence-Socialization Teacher Rating Scale (Carrión et al., 1999) was completed by class tutors one month before the end of the school year, without their being informed of their students' scores on the EF tests or on questionnaires. Students' grades in all subjects were obtained at the end of the school year.

\section{Results}

\section{Data Analyses}

In the first place, descriptive analyses and comparisons between the primary and secondary school samples were carried out with a $t$ test. In the second place, the scores on EF tests were standardized (z scores) for each grade level to enable comparison of performance by group/age. Furthermore, a Pearson correlational analysis was carried out between the EFs measures, the academic performance measures, and the social behavior measures. In the third place, to make the analyses simpler, an exploratory factor analysis was performed following the main component method, with Quartimax oblique rotation, using a scree plot as the factor extraction method, in order to determine the latent structure of the correlation matrix of the EFs, academic performance and social behavior measures. Finally, regression analyses were conducted in each level to test the predictive power of EF scores for school performance and social behavior. The analyses were performed with IBM SPSS Statistics v. 20.

\section{Preliminary Analyses}

The mean and standard deviations, the $t$ test results for the EF task and the questionnaires for each group are included in Table 1. Secondary school students obtained higher scores than primary school students in all EFs measures. Differences in academic achievement were not significant. Differences between primary and secondary school peer tests of social behavior were not found. Lastly, teacher perceived prosocial behavior was higher in primary school students than in secondary school.

\section{Analysis of EF measures}

Table 2 shows the Pearson correlations between the measures obtained from the EF-related tasks, the majority of which were significant, particularly between sub-parts of the same test. The factor analysis showed the existence of three latent variables that explained $69 \%$ of variance, and which corresponded to each of the different tasks: the three VF tests, the two parts of the TMT, and the two parts of the Stroop Test. VF tests explained $37 \%$ of variance, TMT 19\%, and Stroop 13\%.

\section{Analysis of school performance measures}

The Pearson correlation between the GPAs and the class tutor assessments of students' academic skills (I-TRS) was high throughout the sample ( $r=0.77$, $p=.001)$, and also when students were divided into primary $(r=0.81, p=.001)$ and secondary school $(r=0.74, p=.001)$; accordingly, a factor analysis was performed using data from all participants. The result indicated that a single factor accounted for most of the total variance $(88.6 \%)$. There was also a strong correlation between this factor and the two achievement measures ( $r=.94$ in both cases).

\section{Analysis of social behavior measures}

When the same method of analysis was applied to social behavior measures of the total sample, significant correlations were found between all values. However, when primary school students were differentiated from secondary school students, the correlation pattern changed. Pearson correlations remained moderate to high between 
Table 1. Descriptive statistics and mean differences analysis between primary and secondary school

\begin{tabular}{|c|c|c|c|c|c|c|c|c|c|}
\hline & \multicolumn{2}{|l|}{ Primary } & \multicolumn{2}{|c|}{ Secondary } & \multirow[b]{2}{*}{$t$} & \multirow[b]{2}{*}{$p$} & \multicolumn{2}{|c|}{$95 \% \mathrm{CL}$} & \multirow[b]{2}{*}{$F$} \\
\hline & $M$ & $S D$ & $M$ & $S D$ & & & $L L$ & $U L$ & \\
\hline VF- Animals & 14.69 & 5.00 & 16.44 & 5.13 & -2.31 & .022 & -3.24 & -.25 & .044 \\
\hline VF- Letter P & 8.71 & 3.52 & 10.13 & 3.47 & -2.69 & .008 & -2.45 & -.38 & .042 \\
\hline VF- Verbs & 10.64 & 5.09 & 15.52 & 5.94 & -6.37 & .000 & -6.38 & -3.37 & 2.04 \\
\hline TMT- A & 47.61 & 18.04 & 39.19 & 14.04 & 2.82 & .006 & 2.52 & 14.32 & 2.85 \\
\hline TMT-B & 114.57 & 52.26 & 98.98 & 35.05 & 2.36 & .019 & 2.57 & 28.60 & 5.72 \\
\hline Stoop-c & 1.91 & .36 & 2.08 & .31 & -2.97 & .003 & -.27 & -05 & .46 \\
\hline Stroop-cp & .77 & .18 & .85 & .18 & -2.63 & .009 & -.14 & -.02 & .17 \\
\hline Grade Average point & 5.90 & 2.16 & 6.26 & 1.62 & -1.16 & .248 & -.96 & .25 & 8.84 \\
\hline Academic Capacities & 7.06 & 1.67 & 6.72 & 2.07 & .98 & .328 & 2.52 & 14.32 & 3.33 \\
\hline TP-prosocial & 7.01 & 1.50 & 6.36 & 1.79 & 2.16 & .033 & .05 & 1.25 & 2.04 \\
\hline PA-Prosocial & 3.32 & 2.02 & 3.21 & .51 & .69 & .485 & -.21 & .44 & 6.84 \\
\hline Social preference & .004 & .27 & .029 & .129 & -.76 & .447 & -.08 & .03 & 21.58 \\
\hline
\end{tabular}

Note: VF: Verbal Fluency; TMT-A: Trail Making Test (Part A); TMT-B: Trail Making Test (Part B); TP: Teacher-perceived; PA: Peer-assessed.

Table 2. EF measure correlation matrix

\begin{tabular}{|c|c|c|c|c|c|c|}
\hline & TMT-B & VF- A & VF- LP & VF- V & Stroop C & Stroop CP \\
\hline TMT- A & $.420^{* *}$ & $-.291^{* *}$ & $-.286^{* *}$ & $-.329^{* *}$ & $-.255^{*}$ & $-.273^{*}$ \\
\hline TMT-B & & -.160 & $-.276^{*}$ & $-.274^{*}$ & $-.327^{* *}$ & $-.436^{* *}$ \\
\hline VF- A & & & $.504^{* *}$ & $.322^{* *}$ & .125 & $.186^{*}$ \\
\hline VF- LP & & & & $.433^{* *}$ & $.191^{*}$ & $.248^{* *}$ \\
\hline VF- V & & & & & .096 & $.206^{*}$ \\
\hline Stroop C & & & & & & $.517^{* *}$ \\
\hline
\end{tabular}

Note: TMT-A: Trail Making Test (Part A); TMT-B: Trail Making Test (Part B); VF-A = Verbal Fluency, Animals; VF-LP: Verbal Fluency, letter P; VF-V: Verbal Fluency, Verbs.

${ }^{*} p<.05 .{ }^{* *} p<.01$.

all measures for primary students, while for secondary school students a high correlation $(r=.61, p<.01)$ was found solely between peer-evaluated prosocial behavior and the social competence scores provided by class tutors (S-TRS). The correlation between scores for peerevaluated social preference and social competence scores provided by class tutors (S-TRS) was not significant $(r=.17)$. In the light of these results, separate exploratory factor analyses were performed for primary and secondary school students to include the three measures, and repeating the factor extraction procedure. In primary school students, a single factor for Social Behavior explained the variance $(76,5 \%)$ of the three measures, which were strongly correlated to this factor (peer-evaluated prosocial behavior $=0.90$; peer social preference $=.63$; and S-TRS $=.786$ ). In secondary school students, however, two factors were obtained: the first (Prosocial Behavior) explained $61.4 \%$ of variance and included peer-evaluated prosocial behavior and S-TRS scores; the second (Social Preference), which explained $27.8 \%$ of variance, was saturated with peer social preference scores.

\section{Multiple Regression Analysis}

Table 3 shows the correlation matrix of EFs measures and academic and social performance. The factors obtained from the previous factor analyses were used for regression analysis. EF-related variables were included as predictor variables: TMT (A and B), VF (animals, verbs, and the letter $\mathrm{P}$ ), and the Stroop test (Stroop-C and Stroop-PC). Academic Performance and Social Behavior were included as dependent variables for primary school students; School Performance and the two factors associated with social behavior at secondary school level, i.e. Prosocial Behavior and Social Preference, were included for secondary school students. 
Table 3. Correlation matrix of EFs measures and academic and social performance

\begin{tabular}{|c|c|c|c|c|c|c|c|c|c|c|}
\hline & \multicolumn{5}{|c|}{ Primary } & \multicolumn{5}{|c|}{ Secondary } \\
\hline & GAP & $\mathrm{AC}$ & TP-P & PA-P & SP & GAP & $\mathrm{AC}$ & TP-P & PA-P & SP \\
\hline VF- Animals & .14 & .20 & .19 & .12 & .22 & .04 & .10 & .08 & .12 & .12 \\
\hline VF- Letter P & .12 & $.29^{*}$ & $.18^{*}$ & .13 & .09 & .05 & .12 & $.24^{*}$ & $.25^{* *}$ & .06 \\
\hline VF- Verbs & $.58^{* *}$ & $.52^{* *}$ & $.21^{*}$ & .19 & $.32 *$ & $.40^{* *}$ & $.43^{* *}$ & $.38^{* *}$ & $.22^{*}$ & .10 \\
\hline TMT- A & $-.48^{* *}$ & $-.45^{* *}$ & $-.21^{*}$ & -.15 & -.08 & $-.21^{*}$ & -.22 & -.11 & $-.30^{*}$ & -.03 \\
\hline TMT-B & $-.54^{* *}$ & $-.50^{* *}$ & $-.48^{* *}$ & $-.48^{* *}$ & $-.50^{* *}$ & $-.42^{* *}$ & $-.32^{*}$ & $-.33^{*}$ & $-.32^{* *}$ & -.12 \\
\hline Stoop-c & $.42^{* *}$ & $.33^{*}$ & $.32^{*}$ & .23 & $.24^{*}$ & .18 & .03 & .06 & .07 & .04 \\
\hline Stroop-cp & $.43^{* *}$ & $.38^{*}$ & $.38^{*}$ & $.34^{*}$ & $.26^{*}$ & .21 & .03 & .11 & .15 & -.12 \\
\hline
\end{tabular}

Note: GAP: Grade Average Point; AC: Academic Capacities; TP-P: Teacher-perceived prosocial; PA-P: Peer-assessed prosocial; SP: Social preference; TMT-A: Trail Making Test (Part A); TMT-B: Trail Making Test (Part B); VF: Verbal Fluency;

${ }^{*} p<.05 .{ }^{* *} p<.01$.

The first hierarchical regression analyses were performed to determine the predictive power of EF measures for academic performance. As shown in Table 4, in the primary student sample, all EF tests produced significant values, with TMT showing the greatest predictive power. The final model explained $41 \%$ of variance in School Performance. In the secondary school sample, a significant model was also obtained, although only the TMT showed significant predictive power. This model explained 13\% of variance.

The second set of analyses was made to determine the predictive power of EFs for Social Behavior. All EF- and student age-related factors were included as predictor variables. In the primary school sample, the model was significant for the TMT and the Stroop task (see Table 3), and the TMT showed greater predictive power (explaining 29\% of variance). Two regression models were used for secondary school level: the first, to predict the Prosocial Conduct factor, and the second, the Social Preference factor. Again, predictions of TMT and the Stroop Task for Prosocial Behavior were significant, the former being more predictive and that which explained $15 \%$ of variance. However, neither model predicted Social Preference ${ }^{2}$.

\footnotetext{
${ }^{2}$ A Hierarchical Multiple Regression Analysis was carried out in order to confirm whether the influence of EFs on social behavior is independent from gender and academic achievement. The prosocial behavior of all students was included a dependent variable. In the first part, gender was included, in the second one the Academic Performance measures, and in the third one the EF measures. The results of the first model were significant, $R^{2}=.04, \beta=.20, F=5.82, d f=1,134, p=.017$. In the second one, a change in the adjustment is obtained, $R^{2}=.23$, $F=20.08, d f=2,133, p<.001$. The change is also significant when including the EF measures, $R^{2}=.28, F=17.11, \mathrm{df}=3,132, p=.004$, being the TMT scores the ones with most predictive power $(\beta=.241)$. The predictive power of the EFs, especially of the TMT, remains independent from gender and Academic Performance.
}

\section{Discussion}

The results confirmed that the EFs were related to school performance in children and pre-adolescents. Furthermore, they predicted social behavior in primary and secondary school students, with important nuances depending on grade level. The TMT showed the greatest predictive power of the EF tasks. EFs explained $41 \%$ of the variance in school performance in primary school and $13 \%$ of the variance in secondary school students. In primary school, EFs explained 29\% of the variance in Social Behavior while in secondary school they only predicted Prosocial Behavior (15\% of variance), but not Social Preference.

The predictive power of the EF measures used in this study was similar to the findings reported by other studies which used a greater number of tasks to evaluate the EFs. In addition, they were predictive of social behavior regardless of academic performance, especially at primary school. Naglieri and Das (1997) found a similar correlation $(r=0.49)$ between EF measures and overall academic performance but they used a greater number of tasks. This study explains approximately $41 \%$ of variance in school performance in primary students and the tasks used were simple and quick to deliver. The tasks require engagement and the coordination of several EF components that are fundamental to responding to the academic demands associated with mathematics (Lan, Legare, Ponitz, Li, \& Morrison, 2011) and literacy (Monette, Bigras, \& Guay, 2011). It may be that the use of tasks that contain more than one component of EFs allow such a high correlation.

The variance that the EFs explain for academic performance and social behavior is limited. Apart from the EFs, other factors also influence them. Study habits, class participation or teacher-student relationship are also highly relevant for the students' academic 
Table 4. Multiple regression analysis: EF predictors of School Performance and Social Behavior for each grade level

\begin{tabular}{|c|c|c|c|c|c|c|}
\hline DV & Grade level & Predictor & $\beta$ & $p$ & $R^{2}$ & $F$ \\
\hline \multirow[t]{4}{*}{ School Performance } & \multirow[t]{3}{*}{ Primary } & TMT & .47 & .000 & \multirow[t]{3}{*}{.41} & \multirow[t]{3}{*}{$19.4^{* *}$} \\
\hline & & Stroop & .28 & .001 & & \\
\hline & & VF & .20 & .035 & & \\
\hline & Secondary & TMT & .38 & .003 & .13 & $4.82^{* *}$ \\
\hline \multirow[t]{2}{*}{ Social Behavior (prosocial \& social preference) } & \multirow[t]{2}{*}{ Primary } & TMT & .41 & .000 & \multirow[t]{2}{*}{.29} & \multirow[t]{2}{*}{$15.23^{* *}$} \\
\hline & & Stroop & .35 & .000 & & \\
\hline \multirow[t]{2}{*}{ Prosocial Behavior } & \multirow[t]{2}{*}{ Secondary } & TMT & .35 & .001 & \multirow[t]{2}{*}{.15} & \multirow[t]{2}{*}{$5.30^{* *}$} \\
\hline & & VF & .26 & .034 & & \\
\hline Social Preference & Secondary & \multicolumn{4}{|c|}{ Model not significant } & \\
\hline
\end{tabular}

Note: TMT: Trail Making Test; VF: Verbal Fluency; Stroop: Stroop Test.

${ }^{*} p<.05 .{ }^{* *} p<.01$.

performance (Eisenberg, Valiente, \& Eggum, 2010; Valiente, Swanson, \& Lemery-Chalfant, 2012). Empathy has a direct influence on the students' interpersonal relationships (Immordino-Yang, 2011; Valiente, LemeryChalfant, \& Swanson, 2010; Zorza, Marino, \& Mesas, 2015), which improves their immersion in the classroom. It is possible that the predictive power of the EFs on academic performance and on social behavior increases when these variables are added in a multicausal way.

In both primary and secondary school students, the factor comprising the two TMT sub-tests reported the highest predictive values for school performance. The TMT-B evaluates working memory and set shifting, while TMT-A is associated mainly with visual search speed (Sanchez-Cubillo et al., 2009). They also require a good motor performance. Accordingly, it might possibly be the most 'complex' of all the tasks used. Abstract reasoning and planning are basic requirements for many school tasks, and they are skills that depend on working memory and cognitive flexibility (Diamond, 2013). The lower predictive power of execution observed in the TMT among secondary school students may be due to the fact that these cognitive skills have been partially automated at that age (Best et al., 2011).

The predictive power of EFs for social behavior was lower than for school performance; however, it remained significant, particularly in primary school students. In addition, the TMT was the task that reported the greatest predictive value, thus confirming that working memory and cognitive flexibility are basic processes associated not only with academic abilities, but also with regulation of behavior in general (Diamond, 2013). The direct associations found between EFs and social behavior suggest that socio-emotional processes and reactions are partially regulated by EFs (Beauchamp \& Anderson, 2010; Riggs et al., 2006).
Empathy and emotional regulation are enhanced by effortful control (Schultz, Izard, Stapleton, BuckinghamHowes, \& Bear, 2009) and students' prosocial behavior, and their acceptance or rejection by peers is associated with their capacity to empathize and regulate their emotions (Zorza et al., 2013).

In the secondary school student group, the predictive power of EFs for social behavior was lower. Besides, VF performance predicts prosocial behavior significantly, which had not observed in primary school. It is possible that the varied EFs involved in the VF tests are more relevant after childhood since pre adolescents widen their emotional regulation strategies in interpersonal situations (Steinberg, 2005). During childhood, inhibitory control is usually used to regulate reactive aggression o impulsive behavior (Hay et al., 2004). During adolescence, social cognition abilities widen (Blakemore \& Choudhury, 2006) and the use of more cognitive affective regulation strategies, such as reappraisal (Gross, 2008), which are probably more related to the semantic control required in VF tests, gradually increases.

On the other hand, of the EFs measures predicted peer social preference among secondary school students. Unlike in childhood, secondary school students value attributes which are more influenced by adolescents' own subcultures. Characteristics such as playing a sport, looking fit, taking care of one's appearance, and being cool may be more relevant than good school performance (Rodkin et al., 2000). When a peer has low executive control resources and shows impulsive and aggressive behaviors, the teenager does not necessarily reject them (Stormshak et al., 1999). Rejection might require behaviors that make interpersonal relationships extremely difficult, such as when there is deficit of attention and hyperactivity or externalizing behavior problems (Hay et al., 2004; Stormshak et al., 1999). 
The global measures of EFs used in this study, especially the TMT, may be useful for making rapid assessments in large groups of students in order to obtain information about whether it would be advisable to foster self-control activities that lead to better academic performance and coexistence at school. They could also be used to make a quick evaluation of the efficiency of educational intervention programs. The predictive power of EF complex tasks in both the academic and social domain may be due to the fact that they involve several executive processes simultaneously and are associated with self-regulation processes or effortful control (Diamond, 2013; Pessoa, 2009). These tasks give them greater ecological significance (Chan et al., 2008), particularly in a school environment where complex demands require motivational effort and emotional regulation from students. The new generation of EF tests such as the tests described by Chan et al. (2008) provide more precise information on EFs specific elements, and can be used for a more specific evaluation of certain students, but they can have lower predictive power for the global performance school measures (Best et al., 2011). Finally, generalization about these proposals should be cautiously made. The participants' sample is small. Besides, they belong to a middle-low socio-economic level and to Spanish public schools located in quite large cities. Future investigations will require the confirmation of the same pattern of relationships in bigger samples and from different socio-cultural contexts.

\section{References}

Adolphs R. (2009). The social brain: Neural basis of social knowledge. Annual Review of Psychology, 60, 693-716. http:/ /dx.doi.org/10.1146/annurev.psych.60.110707.163514

Altemeier L. E., Abbott R. D., \& Berninger V. W. (2008). Executive functions for reading and writing in typical literacy development and dyslexia. Journal of Clinical and Experimental Neuropsychology, 30, 588-606. http:/ / dx.doi. org /10.1080/13803390701562818

Beauchamp M. H., \& Anderson V. (2010). SOCIAL: An integrative framework for the development of social skills. Psychological Bulletin, 136(1), 39-64. http:/ / dx.doi.org/ 10.1037 /a0017768

Best J. R., Miller P. H., \& Naglieri J. A. (2011). Relations between executive function and academic achievement from ages 5 to 17 in a large, representative national sample. Learning and Individual Differences, 21, 327-336. http:/ / dx.doi.org/10.1016/j.lindif.2011.01.007

Blair C., \& Diamond A. (2008). Biological processes in prevention and intervention: The promotion of selfregulation as a means of preventing school failure. Development and Psychopathology, 20, 899-911. http://dx. doi.org/10.1017/S0954579408000436

Blakemore S-J., \& Choudhury S. (2006). Development of the adolescent brain: Implications for executive function and social cognition. Journal of Child Psychology and Psychiatry,
47, 296-312. http:/ / dx.doi.org/10.1111/j.1469-7610. 2006.01611.x

Carrión A., Hernández P., \& Gregorio F. (1999). Escala de Valoración del Profesor I-S [Teacher Assessment Scale I-S]. Anales de Psicología, 15, 233-238.

Chan R. C. K., Shum D., Toulopoulou T., \& Chen E. Y. (2008). Assessment of executive functions: Review of instruments and identification of critical issues. Archives of Clinical Neuropsychology, 23, 201-216. http:/ / dx.doi. org/10.1016/j.acn.2007.08.010

Checa P., Rodríguez-Bailón R., \& Rueda M. R. (2008). Neurocognitive and temperamental systems of selfregulation and early adolescents' social and academic outcomes. Mind, Brain, and Education, 2, 177-187. http:/ / dx.doi.org/10.1111/j.1751-228X.2008.00052.x

Diamond A. (2013). Executive functions. Annual Review of Psychology, 64, 135-168. http:/ /dx.doi.org/10.1146/ annurev-psych-113011-143750

Eisenberg N., Spinrad T. L., \& Eggum N. D. (2010). Emotion-related self-regulation and its relation to children's maladjustment. Annual Review of Clinical Psychology, 6, 495-525. http:/ /dx.doi.org/10.1146/ annurev.clinpsy.121208.131208

Eisenberg N., Valiente C., \& Eggum N. D. (2010). Selfregulation and school readiness. Early Education and Development, 21, 681-698. http:/ /dx.doi.org/10.1080/ 10409289.2010.497451

Ellis M. L., Weiss B., \& Lochman J. E. (2009). Executive functions in children: Associations with aggressive behavior and appraisal processing. Journal of Abnormal Child Psychology, 37, 945-956. http:/ /dx.doi.org/10.1007/ s10802-009-9321-5

Garon N., Bryson S. E., \& Smith I. M. (2008). Executive function in preschoolers: A review using an integrative framework. Psychological Bulletin, 134, 31-60. http:/ /dx doi.org/10.1037/0033-2909.134.1.31

Gross J. (2008). Emotion regulation. In M. Lewis, J. M. Haviland-Jones, \& L. F. Barrett (Eds.), Handbook of emotions (pp. 497-512). New York, NY: Guilford Press.

Gruber O., \& Goschke T. (2004). Executive control emerging from dynamic interactions between brain systems mediating language, working memory and attentional processes. Acta Psychologica, 115, 105-121. http:/ / dx.doi. org/10.1016/j.actpsy.2003.12.003

Hay D. F., Payne A., \& Chadwick A. (2004). Peer relations in childhood. Journal of Child Psychology and Psychiatry, 45(1), 84-108. http:/ /dx.doi.org/10.1046/j.0021-9630.2003. 00308.x

Hughes C., \& Ensor R. (2008). Does executive function matter for preschoolers' problem behaviors? Journal of Abnormal Child Psychology, 36(1), 1-14. http://dx.doi. org/10.1007/s10802-007-9107-6

Immordino-Yang M. H. (2011). Implications of affective and social neuroscience for educational theory. Educational Philosophy and Theory, 43(1), 98-103. http:/ /dx.doi.org/ 10.1111/j.1469-5812.2010.00713.x

Jacobson L. A., Williford A. P., \& Pianta R. C. (2011). The role of executive function in children's competent adjustment to middle school. Child Neuropsychology, 17, 255-280. http:/ /dx.doi.org/10.1080/09297049.2010.535654 
Jurado M. B., \& Rosselli M. (2007). The elusive nature of executive functions: A review of our current understanding. Neuropsychology Review, 17, 213-233. http:/ / dx.doi.org/10.1007/s11065-007-9040-z

Koren R., Kofman O., \& Berger A. (2005). Analysis of word clustering in verbal fluency of school-aged children. Archives of Clinical Neuropsychology, 20, 1087-1104. http:/ / dx.doi.org/10.1016/j.acn.2005.06.012

Kortte K. B., Horner M. D., \& Windham W. K. (2002). The trail making test, part B: Cognitive flexibility or ability to maintain set? Applied Neuropsychology, 9, 106-109. http:/ / dx.doi.org/10.1207/S15324826AN0902_5

Lan X., Legare C. H., Ponitz C. C., Li S., \& Morrison F. J. (2011). Investigating the links between the subcomponents of executive function and academic achievement: A crosscultural analysis of Chinese and American preschoolers. Journal of Experimental Child Psychology, 108, 677-692. http:/ / dx.doi.org/10.1016/j.jecp.2010.11.001

Lezak M. (1995). Neuropsychological Assessment. New York, NY: Oxford University Press.

López Sánchez F. (2006). El bienestar personal y social y la prevención del malestar y la violencia [Personal and social well-being and prevention of discomfort and violence]. Madrid, Spain: Pirámide.

Maassen G. H., van Boxtel H. W., \& Goossens F. A. (2005). Reliability of nominations and two-dimensional rating scale methods for sociometric status determination. Journal of Applied Developmental Psychology, 26(1), 51-68. http:/ / dx.doi.org/10.1016/j.appdev.2004.10.005

Mahone E. M., Hagelthorn K. M., Cutting L. E., Schuerholz L. J., Pelletier S. F., Rawlins C., ... Denckla M. B. (2002). Effects of IQ on executive function measures in children with ADHD. Child Neuropsychology, 8(1), 52-65. http:/ /dx. doi.org/10.1076/chin.8.1.52.8719

Marino J., Acosta Mesas A., \& Zorza J. P. (2011). Control ejecutivo y fluidez verbal en población infantil: Medidas cuantitativas, cualitativas y temporales [Executive control and verbal fluency in child population: Quantitative, qualitative and temporal measures]. Interdisciplinaria, 28, 245-260.

Miyake A., Friedman N. P., Emerson M. J., Witzki A. H., Howerter A., \& Wager T. D. (2000). The unity and diversity of executive functions and their contributions to complex "frontal lobe" tasks: A latent variable analysis. Cognitive Psychology, 41(1), 49-100. http:/ /dx.doi.org/10.1006/ cogp.1999.0734

Monette S., Bigras M., \& Guay M.-C. (2011). The role of the executive functions in school achievement at the end of Grade 1. Journal of Experimental Child Psychology, 109, 158-173. http:/ /dx.doi.org/10.1016/j.jecp.2011.01.008

Naglieri J. A., \& Das J. (1997). Cognitive Assessment System. Itasaca, IL: Riverside.

Morgan A. B., \& Lilienfeld S. O. (2000). A meta-analytic review of the relation between antisocial behavior and neuropsychological measures of executive function. Clinical psychology review, 20(1), 113-136. http://dx.doi. org/10.1016/S0272-7358(98)00096-8

Pessoa L. (2009). How do emotion and motivation direct executive control? Trends in Cognitive Sciences, 13, 160-166. http:/ /dx.doi.org/10.1016/j.tics.2009.01.006
Piatt A. L., Fields J. A., Paolo A. M., \& Tröster A. I. (1999). Action (verb naming) fluency as an executive function measure: Convergent and divergent evidence of validity. Neuropsychologia, 37, 1499-1503. http:/ / dx.doi.org/ 10.1016/S0028-3932(99)00066-4

Razza R. A., \& Blair C. (2009). Associations among false-belief understanding, executive function, and social competence: A longitudinal analysis. Journal of Applied Developmental Psychology, 30, 332-343. http:/ / dx.doi. org/10.1016/j.appdev.2008.12.020

Riggs N. R., Blair C. B., \& Greenberg M. T. (2004). Concurrent and 2-year longitudinal relations between executive function and the behavior of $1^{\text {st }}$ and $2^{\text {nd }}$ grade children. Child Neuropsychology, 9, 267-276. http:/ /dx.doi. org/10.1076/chin.9.4.267.23513

Riggs N. R., Jahromi L. B., Razza R. P., Dillworth-Bart J. E., \& Mueller U. (2006). Executive function and the promotion of social-emotional competence. Journal of Applied Developmental Psychology, 27, 300-309. http:/ /dx.doi. org/10.1016/j.appdev.2006.04.002

Rodkin P. C., Farmer T. W., Pearl R., \& van Acker R. (2000). Heterogeneity of popular boys: Antisocial and prosocial configurations. Developmental Psychology, 36(1), 14-24. http:/ / dx.doi.org/10.1037/0012-1649.36.1.14

Romer D., Betancourt L., Giannetta J. M., Brodsky N. L., Farah M., \& Hurt H. (2009). Executive cognitive functions and impulsivity as correlates of risk taking and problem behavior in preadolescents. Neuropsychologia, 47, 2916-2926. http:/ /dx.doi.org/10.1016/j.neuropsychologia. 2009.06.019

Rueda M. R., Checa P., \& Rothbart M. K. (2010). Contributions of attentional control to socioemotional and academic development. Early Education and Development, 21, 744-764. http:/ / dx.doi.org/10.1080/10409289.2010. 510055

Sanchez-Cubillo I., Perianez J. A., Adrover-Roig D., Rodriguez-Sanchez J. M., Rios-Lago M., Tirapu J., \& Barceló F. (2009). Construct validity of the Trail Making Test: Role of task-switching, working memory, inhibition/ interference control, and visuomotor abilities. Journal of the International Neuropsychological Society, 15, 438-450. http:/ / dx.doi.org/10.1017/S1355617709090626

Schultz D., Izard C. E., Stapleton L. M., BuckinghamHowes S., \& Bear G. A. (2009). Children's social status as a function of emotionality and attention control. Journal of Applied Developmental Psychology, 30, 169-181. http://dx. doi.org/10.1016/j.appdev.2008.12.002

Steinberg L. (2005). Cognitive and affective development in adolescence. Trends in Cognitive Sciences, 9, 69-74. http:/ / dx.doi.org/10.1016/j.tics.2004.12.005

Stormshak E. A., Bierman K. L., Bruschi C., Dodge K. A., Coie J. D., Greenberg M. T., ... McMahon R. J. (1999). The relation between behavior problems and peer preference in different classroom contexts. Child Development, 70(1), 169-182. http:/ /dx.doi.org/10.1111/1467-8624.00013

Thorell L. B., Lindqvist S., Bergman Nutley S., Bohlin G., \& Klingberg T. (2009). Training and transfer effects of executive functions in preschool children. Developmental Science, 12(1), 106-113. http:/ /dx.doi.org/10.1111/j.14677687.2008.00745.x 
Valiente C., Lemery-Chalfant K., \& Swanson J. (2010) Prediction of kindergartners' academic achievement from their effortful control and emotionality: Evidence for direct and moderated relations. Journal of Educational Psychology, 102, 550-560. http://dx.doi.org/10.1037/ a0018992

Valiente C., Swanson J., \& Lemery-Chalfant K. (2012). Kindergartners' temperament, classroom engagement, and student-teacher relationship: Moderation by effortful control. Social Development, 21, 558-576. http:/ / dx.doi. org/10.1111/j.1467-9507.2011.00640.x

van der Ven S. H. G., Kroesbergen E. H., Boom J., \& Leseman P. P. M. (2012). The development of executive functions and early mathematics: A dynamic relationship. British Journal of Educational Psychology, 82(1), 100-119. http:/ /dx.doi.org/10.1111/j.2044-8279.2011.02035.x

Zorza J. P., Marino J., de Lemus S., \& Acosta Mesas A. (2013). Academic performance and social competence of adolescents: Predictions based on effortful control and empathy. The Spanish Journal of Psychology, 16, E87. http:/ / dx.doi.org/10.1017/sjp.2013.87

Zorza J. P., Marino J., \& Acosta Mesas A. (2015). The influence of effortful control and empathy on perception of school climate. European Journal of Psychology of Education, 30, 457-472. http://dx.doi.org/10.1007/ s10212-015-0261-x 